\title{
PENSAR EN ARTE
}

\author{
$M^{\text {a }}$ José Clavo Sebastián \\ Universidad de La Rioja \\ María Íñigo Clavo \\ Universidad de Complutense de Madrid
}

\begin{abstract}
RESUMEN. Este artículo describe una experiencia de intervención educativa. Su objetivo es facilitar un contacto reflexivo con los aspectos que intervienen en la comprensión del proceso artístico. Va dirigida a alumnos de último curso de Educación Primaria.

ABSTRACT. This article describes an experience of educational intervention. Its objective is to facilitate a thoughtful contact with the cognitive aspects of art to a group of children attending their last year of primary school.
\end{abstract}

\section{Introducción}

Esta experiencia tiene un propósito fundamental: tratar de estimular el pensamiento de los niños orientado a la comprensión del proceso artístico y los problemas que le acompañan.

La enseñanza del arte, como la de cualquier otra asignatura, implica la integración, siempre complicada, de los elementos epistemológicos o conceptuales propios de la materia y los psicopedagógicos. Sabemos que las relaciones entre estos dos ámbitos no son unívocas, como tampoco lo son las distintas opciones psicológicas con respecto al fenómeno de la enseñanza. Existen perspectivas que tienen como fuentes del currículum las teorías psicológicas conductistas, que han contribuido a la formación del paradigma tecnológico del currículum, como las propuestas de Bloom, Hasting y Madaus (1975). Lo atractivo de estas propuestas es la metodología del diseño instruccional que garantiza la efectividad de la enseñanza; otorgan una gran importancia a la evaluación, que intenta hacer posible una valoración objetiva de los aprendizajes. Frente a esta opción se encuentra la de los que defienden un enfoque curricular más cercano a planteamientos cualitativos e interpretativos, sin desatender al carácter sistemático y organizado de estos procesos. Se defiende un modelo interdisciplinar que, abandonando el planteamiento de muchos objetivos de aprendizaje, formula y profundiza en una gran meta global: la capacidad de los alumnos para dar expresión sim- 
bólica a sus ideas y para interpretar los significados de sus "trabajos artísticos" y naturalmente de las obras de los artistas. Podemos incluir en esta orientación los trabajos de Eisner (1971) . Nuestra posición es más cercana a esta concepción de la enseñanza que a la anterior. La psicología de la educación constructivista, en la que está basado gran parte del diseño de los curricula que se derivan del D.C.B. nos proporciona unos medios didácticos de enorme utilidad para nuestros objetivos; aun cuando el auténtico proceso de comprensión del arte no se puede objetivar ni, por tanto, cuantificar, sin embargo, sí puede hacerse con algunos de los objetivos didácticos que nos hemos propuesto como medio para conseguir nuestro objetivo fundamental; no obstante no hemos elaborado un análisis estadístico riguroso de los resultados sino únicamente un análisis cuantitativo aproximado porque lo que nos ha interesado ha sido, sobre todo, el aspecto cualitativo.

Nuestra posición en relación a la comprensión del fenómeno artístico no es cientificista; pensamos que la ciencia, entendida como ciencia positiva, es reduccionista en su modo de abordar la realidad humana, y no puede ser de otro modo porque el objeto de la ciencia es eso, objeto, y toda su metodología se halla construida y preparada para el tratamiento de objetos, de manera que cualquiera que sea su ámbito de investigación requiere previamente ser objetualizado para poder ser abordado. Del mismo modo el ser humano debe también ser transformado en objeto para poder ser estudiado por la ciencia. Y si el hombre posee un aspecto de su realidad objetivable, sin embargo él, en cuanto tal, jamás podrá ser objeto, los aspectos más esenciales de su "humanidad" escapan a la consideración de la ciencia positiva. Y es que esos aspectos son por definición inobjetivables, nos referimos a su ser sujeto, raíz de donde brotan, en interacción con el mundo, absolutamente todos los productos humanos, incluida la ciencia misma. No solamente el ser sujeto del sujeto (como diría Martínez Marzoa) no puede ser objeto de ciencia sino que, además, es la condición de posibilidad de la ciencia misma, la cual surge como actividad vital de determinados seres humanos en su diálogo con el mundo.

Pues bien, el arte, el hecho de la existencia de algo que llamamos arte, se encuadra, desde luego, en un horizonte subjetivo muy complejo irreductible a la cosificación, objetualización y cuantificación de la ciencia. En la dimensión estética hay un juego importante de lo irracional inteligibilizado y encarnado en materia. Entender el arte es comprender esa fuerza que hace surgir, encarnación de la fuerza creadora de la naturaleza misma en el mundo interno del artista, como diría Nietzsche en "El nacimiento de la Tragedia". Lo importante del arte es ese encuentro en profundidad de lo irracional "sin forma" que necesita expresarse y, por lo tanto, hacerse inteligible. Esta dinámica habida en algunos seres humanos afortunados no puede ser explicada de modo científico, como si fuera un hecho positivo ( entendiendo por tal lo que por tal entiende la ciencia positiva), ni tampoco este especial modo de estar en el mundo se puede comprender de otro modo que mediante un movimiento de compenetración con el artista. El arte es fuerza que se concreta en la necesidad de manifestarse, para lo cual busca una forma y una materia en la que exteriorizarse. El pensamiento es una herramienta de inteligibilidad y, a su vez, radical e imprescindible elemento de creatividad. El artista se manifiesta, pero ello requiere un quién ante el cual manifestarse y por el que quiere ser entendido. El otro es, pues, ingrediente esencial de la obra de 
arte; si no hubiera otro, no habría obra, y es en la dimensión social del arte donde surgen importantes problemas: de comunicación, que se manifiestan en la capacidad del espectador para comprender el mensaje; de valoración, es decir del establecimiento de un criterio objetivo para valorar la calidad de las obras japarecen los críticos!; de mercantilización en nuestra sociedad capitalista, elemento adulterador que tiene su peso ¡qué duda cabe! en el mundo interno del artista.

No hemos pretendido escribir un artículo científico sobre didáctica de arte porque, obviamente, este trabajo es una experiencia que describimos por si puede ser de alguna utilidad a otras personas interesadas en estos temas; pero además pensamos que no estamos seguras de que una materia como la didáctica del arte pueda constituirse en ciencia positiva; comprender el arte no es posible sino desde esa dimensión humana irreductible a la ciencia; sólo si conseguimos situarnos y situar a los niños en ese ámbito podemos entender algo acerca de él, de sus problemas y contradicciones.

En cuanto a los contenidos epistemológicos nos enfrentamos con un tema que hasta estas edades ha sido explorado más a nivel práctico que teórico; las orientaciones curriculares de la LOGSE, en lo que respecta al tercer ciclo de educación primaria, se centran en dos aspectos: el perceptual y el expresivo; en cuanto al aspecto perceptual se aconseja el desarrollo de la capacidad de observación sistematizada y la sensibilización frente al hecho artístico; por lo que respecta al nivel expresivo, se trata de promover la adquisición de habilidades para utilizar autónomamentte los elementos artísticos básicos y la incorporación del lenguaje artístico a las formas habituales de expresión. Sin embargo, en sus criterios de evaluación, que son cuatro, sólo uno está dedicado al aspecto perceptual, centrado, sobre todo, en la lectura de la imagen, mientras que los otros tres están dedicados al aspecto expresivo. Ésta debe ser la razón por la que en la práctica docente los niños de estas edades apenas han recibido una formación sensibilizadora, reflexiva y crítica sobre el fenómeno artístico, mientras que sí han trabajado el desarrollo de sus habilidades plásticas.

Nuestro trabajo se ha desenvuelto, sobre todo, en este ámbito escaso en la práctica escolar. Pensamos que la actividad artística sólo puede adquirir significado si la articulamos a la vida humana de donde surge, por esta razón nuestras preocupaciones han sido, sobre todo, situar a los niños en la dimensión interna del arte, tanto desde el artista como desde el espectador; nos ha preocupado que vivieran la subjetividad de la experiencia estética y su relatividad; que concienciaran el papel nuclear del pensamiento en cuanto que traduce la vivencia estética del artista y busca y crea el modo adecuado de expresión de la misma; que se plantearan si la posibilidad de comprender una obra de arte se encuentra, precisamente, en la capacidad para compartir esos pensamientos y que experimentaran la potencialidad del arte para generar pensamientos en el espectador; que descubrieran, por fin, que el arte responde a una necesidad del artista de comunicar algo.

Todas estas reflexiones y experiencias acerca del arte en general las hemos llevado a cabo desde un espacio y tiempo artístico determinado: el arte moderno. La razón por la que nos hemos planteado acercar a los niños a los códigos del arte moderno es porque este ámbito es, para las personas no iniciadas, el más oscuro y difícil de comprender, lo que lo convierte en carente de interés, cuando, en realidad es el más afín a nuestras sensibilidades y motivaciones. En este espacio hemos elegido presentar la pro- 
puesta de Pollock a la reflexión de los niños por las siguientes razones: si llevamos a cabo un recorrido por las diversas formas de entender el trabajo artístico nos encontramos una gran cantidad de puntos de vista muchas veces contradictorios; así, en la Edad Media se presentaba el arte como elemento didáctico ligado a la sublimación humana propia de la época; en el impresionismo tomaba una dirección más empírica por la obsesión y tratamiento de la luz. Con la llegada del siglo XX, los movimientos artísticos se manifiestan cada vez más agresivos, con unos planteamientos más radicales y muchas veces comprometidos socialmente; éste sería el caso del futurismo que busca su temática en el avance tecnológico, la velocidad y la máquina; otro caso es el del dadaismo que se enfrenta, en sus planteamientos, al propio arte para cuestionarlo; o el surrealismo que se desarrolla en paralelo a los avances que iban teniendo lugar en el campo de psicoanálisis. En los años 40 aparece en el panorama artístico una figura que, junto con la de John Cage y Kaprow, abrirá un camino nuevo a las investigaciones artísticas: Jackson Pollock; este artista llevaba a cabo la llamada pintura de acción; con el dripping utilizaba el arte como un elemento terapéutico que reflejaba fielmente su estado de ánimo, es por eso que concedió más importancia al proceso artístico que a la obra terminada. Fue conocido por pintar sus grandes lienzos tendidos en el suelo, en los que salpicaba con la pintura. La obra de Pollock nos proporciona un punto de vista altamente didáctico, el arte como instrumento de bienestar y calidad de vida, como una actividad que aportará algo más que comunicación. Al margen de los circuitos artístico-económicos, Pollock desarrollaba su obra dejando la puerta abierta a los futuros accionistas. Creemos que este tipo de planteamientos son positivos para los niños como punto de partida. La sociedad que los acoge es competitiva y concede gran importancia al triunfo y al fracaso. La idea de utilizar las bases de Pollock tendría que ver con una ruptura de ese tipo de prioridades.

Aun cuando priorizamos el aspecto interno del arte, sabemos que éste es incomprensible si no nos aproximamos al mundo de los elementos plásticos de la obra , y puesto que nuestro tiempo es limitado, hemos elegido acercarnos al espacio pictórico, al que dedicamos una jornada. La razón es que el espacio es una cuestión actualmente vigente en la mayor parte de las manifestaciones artísticas: pintura, escultura, instalaciones, danza etc... El problema de la representación de la realidad está implícito en cualquier discusión que gire en torno al espacio; es importante que el niño encuentre nuevos modos de ver y de hacer y este elemento, el espacio, es uno de los primeros y fundamentales, sobre todo a la hora de materializar sus ideas. Por otra parte, si algún terreno puede ser más accesible es la pintura. Entendemos esta experiencia como una introducción a partir de la cual se puede comenzar a indagar en otros campos, como puede ser el escultórico; constituye, pues, un punto de partida. Los tres autores elegidos son conocidos por las dislocaciones espaciales que muchas veces nos muestran en sus cuadros; así es el caso de Magritte, que crea planos de profundidad en lugares que no corresponden, haciendo cierta alusión al trampa-antojo; Fontana evidencia el plano pictórico rasgando la tela del lienzo, su obra es un primer paso hacia el mestizaje actual entre pintura y escultura; esta obra representa un gran paso en la representación del espacio, nuestro propósito fué utilizarla para pasar al espacio-contexto escultórico y su tratamiento, no dispusimos de tiempo para ello, pero es una vía que queda abierta para otra experiencia; el caso de Picasso es más 
conocido, su deconstrucción del espacio también puede ser un motivador de nuevas formas de ver la realidad.

Por último hacemos una introdución a la problemática social del arte, en cuanto que, desde este ángulo la obra de arte depende del espectador, es decir que el artista parece incapacitado ante la sociedad para valorar su obra y parece que no hay otra manera de consagrarse si ni es por medio de ella, así lo manifestaba Robert Smithson durante una entrevista que más tarde apareció en la publicación "Geometría y Gesto" para tratar el movimiento anti-forma. No podemos olvidar que arte es comunicación, expresión de algo: en nuestro esquema de trabajo incentivamos el arte como experiencia personal, pero por otra parte mostramos contradicciones con las que han de enfrentarse muchos artistas, como por ejemplo encontrar una manera de que su trabajo sea entendido sin por ello dejar de utilizarlo como una forma de autorrealización. Es decir, tratamos de transmitir la pluralidad de posturas por las que se puede optar y de ayudar a los niños a que encuentren la suya. Por esta razón nos movemos en la metodología que planteaba Lipman: el profesor es quien abre la polémica que madurará durante el transcurso de los debates, la tarea del maestro es la de facilitar el descubrimiento de experiencias, realidades, conceptos y valores por parte de los alumnos mediante el ejercicio en común de un pensamiento reflexivo, analítico, crítico.

Los conceptos que utilizamos para presentar el hecho artístico son aquellos que consideramos comunes a cualquier corriente (aún sabiendo que la intencionalidad, por ejemplo, es rechazada por algunos artistas del dadaismo); de esta manera generamos un debate que familiariza a los alumnos con algunas cuestiones de este campo.

Nuestros alumnos han sido 25 niños de entre 11 y 12 años, que asisten a una escuela pública enclavada en un entorno de clase media-baja, por lo que no son niños especialmente cultivados en nada que no sea lo que la escuela misma puede proporcionarles. Hemos intentado que se compenetren con el artista, que experimenten sus motivos, que descubran el pensamiento encerrado en su obra y cómo, a su vez, ésta genera en ellos pensamiento. Algunos de nuestros objetivos se han cumplido, otros no; pero el simple hecho de haber situado a los niños en unas determinadas condiciones que les han animado a producir los pensamientos que han producido, hace que nuestra experiencia haya merecido la pena. Estos pensamientos, para nosotros posiblemente lo más valioso, los transcribimos literalmente, en cursiva, en su lugar temático para no descontextualizarlos. Ellos son la condensación de una reflexión importante sobre los problemas que les hemos presentando, y cada uno de ellos muestra que detrás hay un pequeño filósofo y que gran parte de la filosofía del arte no es sino una explicitación de lo que se encuentra encerrado en estas afirmaciones.

Por último añadir que hemos establecido una dinámica de trabajo de acuerdo con determinadas pautas propias del campo pedagógico. Tan exhaustiva concreción de objetivos, contenidos y demás apartados pudieran resultar repetitivos para lectores que no están familiarizados con este tipo de metodología. Somos conscientes de lo inusual de este tipo de aclaraciones, pero no quisiéramos desanimar a quienes estuvieran interesados en nuestro trabajo y encontraran en todos estos pasos una interferencia hacia el conocimiento de nuestra experiencia. Por ello, y por nuestro deseo de poder llegar a todo tipo de lectores, queremos dar a conocer de antemano una forma más directa para acceder a lo que supondrá la narración de la experiencia realizada 
con los niños día a día: a partir de la segunda parte, la exposición tendrá un carácter más descriptivo, reflexivo, crítico y analítico con respecto a lo sucedido en el aula.

El trabajo consta de tres partes: la primera consiste en la programación de la experiencia; la segunda es una descripción de la realización de la misma a través de cada una de las sesiones que tuvimos con los niños y la tercera es la exposición y valoración de los resultados en relación con los objetivos que nos habíamos propuesto.

\section{1o Parte: Programación de la experiencia}

\section{Objetivos}

Como primer criterio didáctico para establecer nuestros objetivos, hemos tenido en cuenta el estadio evolutivo de los alumnos. Son estudiantes de último curso de Educación Primaria (sexto curso), por lo que se encuentran en un estadio de desarrollo operatorio formal, lo que significa que tienen ya la capacidad de manejar conceptos abstractos sin dificultad.

De los tres elementos que componen el proceso de enseñaza/aprendizaje: contenidos, actividades, resultados, hemos utilizado una vía mixta de acceso para concretar nuestros objetivos: los contenidos (entendidos en el sentido amplio)/resultados. Por ello, a partir de un análisis de los posibles contenidos de la enseñanza, seleccionando los que poseen mayor valor formativo y de los resultados que de ellos deberían derivarse, hemos concretado nuestros objetivos.

Los objetivos que nos planteamos son más los llamados de tipo expresivo que instructivos, que no excluyen las posibilidades de introducir variaciones sino que por el contrario describen "situaciones de aprendizaje": es decir, intentamos poner al alumno en situaciones que luego puedan identificar pero sin dictaminar una manera estereotipada de comportarse frente a ellas.

\section{A- Objetivos Generales}

- Comprensión del proceso artístico

- Mirar y apreciar el arte

- Discutir y debatir la naturaleza del arte

- Potenciar el pensamiento divergente

\section{B- Objetivos Didácticos}

- Asimilación de los conceptos fundamentales que exponemos en los contenidos.

- Toma de conciencia de que en el arte no hay una sola solución.

- Interpretación y reflexión.

- Elección de las opciones más válidas de pensamiento para cada uno sin temer que otras opiniones invaliden la propia.

- Acercamiento y discusión sobre los códigos de las vanguardias: el arte abstracto, Pollock, Magritte...

- Experimentación del proceso artístico desvinculado del resultado final.

- Introducción a la problemática social del arte: relación artista-espectador. 
Existe una interdependencia obvia entre todos estos objetivos de manera que no se pueden entender de una forma aislada.

\section{Contenidos}

Puesto que en nuestras intervenciones didácticas nos propusimos facilitar un primer contacto de los niños con el arte, identificamos los elementos fundamentales del contenido y los organizamos en un esquema jerárquico y relacional tratando de facilitar una estructura de conocimiento en la que poder integrar posteriormente el mayor número de los elementos restantes (como veremos al exponer la secuenciación o temporalización de los contenidos).

Estos elementos fundamentales del contenido los agrupamos en conceptos, procedimientos y actitudes.

A- Conceptos

- Los que constituyen los elementos esenciales del arte actividad intencionada creativa productora de algo material

- El arte, inherente a la condición humana

- La relatividad de la experiencia estética

- El pensamiento y la creación

- Diferencia entre el arte como producto y como proceso

- Diferencia entre el arte abstracto y el figurativo

- Conocimiento de una postura real: Jackson Pollock

- Interpretación. El espacio pictórico.

- El arte como medio de comunicación emisor-mensaje-receptor lo objetivo lo subjetivo conexión emisor-receptor

- Problemática social del arte y el artista: artista - espectador.

B-Procedimientos

- Lectura de la obra artística

- Dialogar

- Producción artística

- Expresión escrita de los propios pensamientos y reflexiones

\section{C-Actitudes}

Actitudes positivas hacia el arte, que deben concretarse en las posibles visitas a exposiciones, mediante la comprensión del proceso artístico y la realidad del artista. 


\section{Metodología}

Incluimos en este apartado los aspectos referentes a la organización y secuenciación del contenido, los materiales empleados y los procedimientos didácticos.

\section{A- Organización y secuenciación del contenido}

En la organización de los temas hemos tenido en cuenta, siguiendo la propuesta de Ausubel y Novak, la estructura lógica del contenido y hemos tratado de compatibilizarla con una adecuada secuenciación de acuerdo con la estructura psicológica de los alumnos, es decir, de acuerdo con los principios que rigen la formación y desarrollo de su estructura cognoscitiva.

Para ello, hemos identificado, en primer lugar, los elementos fundamentales del contenido y los hemos organizado en un esquema jerárquico y relacional a partir de los elemementos de máxima generalidad en los que se pueden ir integrando otros más específicos.

Nos propusimos, entonces, presentar al principio los conceptos más generales para favorecer con ello la formación de conceptos inclusores en la estructura cognoscitiva de los alumnos, lo que, a su vez, permitiría el posterior aprendizaje significativo de los otros elementos. Después de presentar los conceptos más generales, pensamos introducir los elementos más específicos mostrando sus relaciones tanto con los primeros como entre ellos, para facilitar, así, la comprensión de la diferenciación progresiva a la vez que la integración de los conceptos.

Establecimos una jerarquía conceptual en una secuencia lógica descendente que hicimos coincidir con la secuencia temporal en la que pensamos presentarles los conceptos:

Día I. Presentación de los conceptos básicos constituyentes de lo que llamamos actividad artística, porque los consideramos imprescindibles para poder empezar a entender el arte y porque son los conceptos más generales a partir de los cuales podemos ir presentando los demás por explicitación y diferenciación .

Día II. Nos centramos en el aspecto interno del arte desde el artista (primero): la experiencia estética penetrada de pensamiento es el germen de la producción.

El espectador (después) puede entender la obra si es capaz de leer estos pensamientos en la experiencia estética subjetiva que los produce. Puede, también crear sus propios pensamientos a partir de ella.

De modo que trabajaremos:

- La relatividad de la experiencia estética.

- La importancia del pensamiento tanto en el artista como en el espectador.

Día III. En esta tercera sesión nos situamos en el arte como obra hecha desde el punto de vista del artista. Debate entre dos posiciones: arte como producto de un proceso, o arte en el que se considera el proceso mismo como el producto.

A partir de ahí introducción de los conceptos de arte figurativo y arte abstracto. 
Día IV. Continuamos situados en el ámbito del arte como obra hecha, pero desde el punto de vista del espectador. Relatividad de la experiencia estética. Toma de conciencia del espacio y su importancia en el arte.

Día V. Preparados para hablar del arte como lenguaje. A partir de ello introducir los conceptos de:

- artista-emisor - obra de arte-mensaje - espectador-receptor

- lo objetivo y lo subjetivo

- los grandes problemas de la comunicación artística:

- conexión a partir de aspectos subjetivos (experiencia estética)

- lectura aspectos cognitivos (pensamiento)

- problemas específicos del entorno artístico en relación con la sociedad.

\section{B- Materiales}

- Tres textos presentados como pequeñas narraciones, acompañados de preguntas sobre los mismos adecuadas para trabajar :

- Los conceptos constitutivos de la actividad artística

- Diferencia entre el arte entendido como producto y como proceso

- Problemática del arte como acto de comunicación y todos los elementos que lo integran

- Diapositivas para trabajar:

- La importancia del pensamiento

- La subjetividad de la experiencia estética

- Diferencia arte figurativo-arte abstracto

- Experiencia del espacio pictórico

- Cuadernos de clase

- Folios y pinturas escolares (de las que ellos utilizan)

- Magnetófono y cinta de música

- Grabadora de vídeo para grabar las sesiones y analizarlas posteriormente.

\section{C- Procedimientos didácticos}

Los procedimientos didácticos vienen determinados por los objetivos propuestos, la secuenciación lógica de los contenidos y por la opción de aprendizaje elegida. Encuadrados en la orientación constructivista, se trataba de llevar a cabo una intervención pedagógica que creara las condiciones adecuadas para que los esquemas de conocimiento que construyen los alumnos evolucionaran en la dirección de nuestros objetivos. Deseábamos que la nueva información que les íbamos a ir presentando fuera incorporada y asimilada a sus esquemas previos de modo que éstos se fueran modificando en la orientación que nos propusimos. Para ello pensamos utilizar: 
- El diálogo, que les permitiría ampliar sus esquemas previos mediante el ejercicio de descubrimiento de conceptos y de precisión conceptual, a través del razonamiento y de las aportaciones cognitivas del grupo.

- Presentación de diapositivas para posibilitarles experimentar de una forma abierta la realidad hermenéutica del arte, la posible función del mismo como estímulo de pensamiento y la diferencia del arte abstracto y figurativo desde su posición de receptores, es decir, como vivencia.

- Sesión de pintura con música electrónica, con objeto de experimentar la propuesta que Jackson Pollock planteó para su trabajo: el resultado es el propio proceso. En ella podrían vivir la experiencia del arte como medio de comunicación de sentimientos, emociones o pensamientos a partir de una premisa común, la música y las bases del trabajo del artista Pollock. Por otra parte una perspectiva del arte más como proceso que como algo destinado a la aceptación social.

- Una sesión en la que elaborar entre todos el esquema de los elementos generales de la comunicación social y sus relaciones, su aplicación a la relación artista-espectador y los problemas que ello trae consigo.

- Todos los alumnos deberán hacer un cuaderno en el que escribirán cada día sus reflexiones acerca de lo debatido en clase y su posición razonada en torno a los temas tratados. Ello vigorizará su proceso de formación de esquemas de conocimiento y sus actitudes.

\section{Evaluación}

En el contexto en el que nos encontramos, la evaluación debe cumplir dos funciones; una, posibilitar la toma de conciencia de las sucesivas situaciones didácticas, con objeto de poder ajustar progresivamente la ayuda pedagógica a las características de los alumnos; y otra, comprobar si se han cumplido o no o hasta qué punto, los objetivos que nos propusimos.

De modo que pensamos en hacer cuatro tipos de evaluación:

- una evaluación inicial en la que hacernos cargo de los conocimientos de los alumnos para la nueva situación de aprendizaje

- una evaluación formativa del proceso para ir ajustando las intervenciones didácticas a las necesidades y posibilidades del grupo

- una evaluación final mediante un cuestionario que les haremos al finalizar todas las sesiones.

- una evaluación global para comprobar sí y hasta qué punto se han cumplido los objetivos.

\section{2ª Parte: realización de la experiencia}

A continuación vamos a describir la experiencia tal como la vivimos día a día. Incluye:

La descripción de las sesiones

La evaluación de la prueba final. 
Descripción de las sesiones

Constan de la programación del día, los procedimientos y realización, y la valoración de la sesión .

1a SESIÓN

Objetivos: Asimilación de los conceptos básicos

Contenidos:

Conceptos: Arte: actividad-intencionada -creativa - productora de algo material

Procedimientos: Lectura en común

Reflexión y cuestionamiento del contenido

Formulación de preguntas

Diálogo

Expresión escrita de sus reflexiones

Actitudes: Cognitivas hacia el fenómeno arte

Materiales: Texto $1^{\circ}$

Procedimiento y realización

Para introducirles al tema leimos entre todos una historia ( incluida en la sección de materiales).

Tras la lectura los alumnos hicieron preguntas sobre la misma, que fuimos apuntando una a una en la pizarra, junto con el nombre del niño que la había formulado.

A continuación escogimos la que creímos que se adecuaba más a los conceptos que deseábamos introducir y a partir de ahí iniciamos una discusión sobre cuáles son las condiciones que han de darse para que tenga lugar el acto artístico siempre desde una perspectiva muy amplia y general: actividad, intencionada, creativa, con un resultado final.

Todos estos conceptos fueron saliendo de una manera bastante natural de las intervenciones de los niños al expresar sus pensamientos. Les pedimos que escribieran en su cuaderno lo acontecido durante la sesión y su opinión acerca de ella. Estas estaban bastante repartidas: algunos mencionaron los conceptos de los que habíamos hablado: la intencionalidad, la creatividad, el pensamiento y la expresión que hasta ahora era un tema que no había salido de forma programada. Muchos identificaban el arte como un lugar destinado a los famosos y al dinero, algunos también hablaron de las copias. Sólo uno mencionó que es necesario entender.

"Porque el arte es una de esas cosas en la que es muy fácil dar ejemplos pero sin embargo no es tan fácil definir"

El debate nos sirvió para explicitar, precisar y sistematizar los conceptos y, en fin, facilitar a los alumnos la formación de un esquema de conocimiento sobre el tema.

\section{2a SESIÓN}

Objetivos: Nos propusimos situar al niño en el aspecto interno del arte desde el artista (primero) y hacerle descubrir que el pensamiento penetrado por la experiencia 
estética es el germen de la producción; que el espectador (después) puede entender la obra si es capaz de leer estos pensamientos en la experiencia estética subjetiva que le produce y que puede, también, crear sus propios pensamientos a partir de ella.

De modo que trabajaremos los contenidos siguientes:

Conceptos:

Pensamiento y creación

Relatividad de la experiencia estética

Procedimientos:

Dialogar

Aprender a ver:

- el pensamiento encerrado en la obra

- el pensamiento que crea en ellos la obra

- la subjetividad de la experiencia estética

Poner títulos a las obras que van a ver en diapositivas

Escribir sus opiniones razonadas sobre el

problema que les pensamos plantear.

Actitudes:

- Valoración de la importancia que el pensamiento tiene en la creación y contemplación del arte.

- Valoración de su propia experiencia estética

- Aceptación y respeto hacia otras diferentes

Materiales:

Diapositivas:

Chagall: "París por la ventana" (1913) (no 1)

Giacometti: "La nariz" (1947) ( no 2)

Jackson Pollock: detalle de la obra "Composición 16" (1948) (no3).

Procedimientos y realización:

Para empezar hicimos un pequeño repaso de las conclusiones del día anterior.

Basándonos en éstas les preguntamos si ellos como creadores necesitarían del pensamiento para hacer sus obras. La mayoría estaba de acuerdo en que sí lo necesitarían y ponían ejemplos.

A continuación planteamos la pregunta de si pensar sobre arte, planificar proyectos que luego no se llevan a cabo podría considerarse arte; es decir, la obra desligada de un resultado concreto. Les propusimos una situación: yo, como artista tengo un proyecto muy elaborado e ingenioso y lo cuento a mis amigos, pero no llego a realizarlo, ¿mis ideas son arte? La mayoría piensa que no porque la obra ha de ser vista.

Después pusimos tres diapositivas y preguntamos a qué personas les gustaban y a cuáles no. A partir de ahí comenzó un pequeño debate en el que cuestionamos cuál 
sería el criterio para decidir si una obra es buena o mala. Les pedimos que escribieran cada uno en su cuaderno la respuesta a esta pregunta.

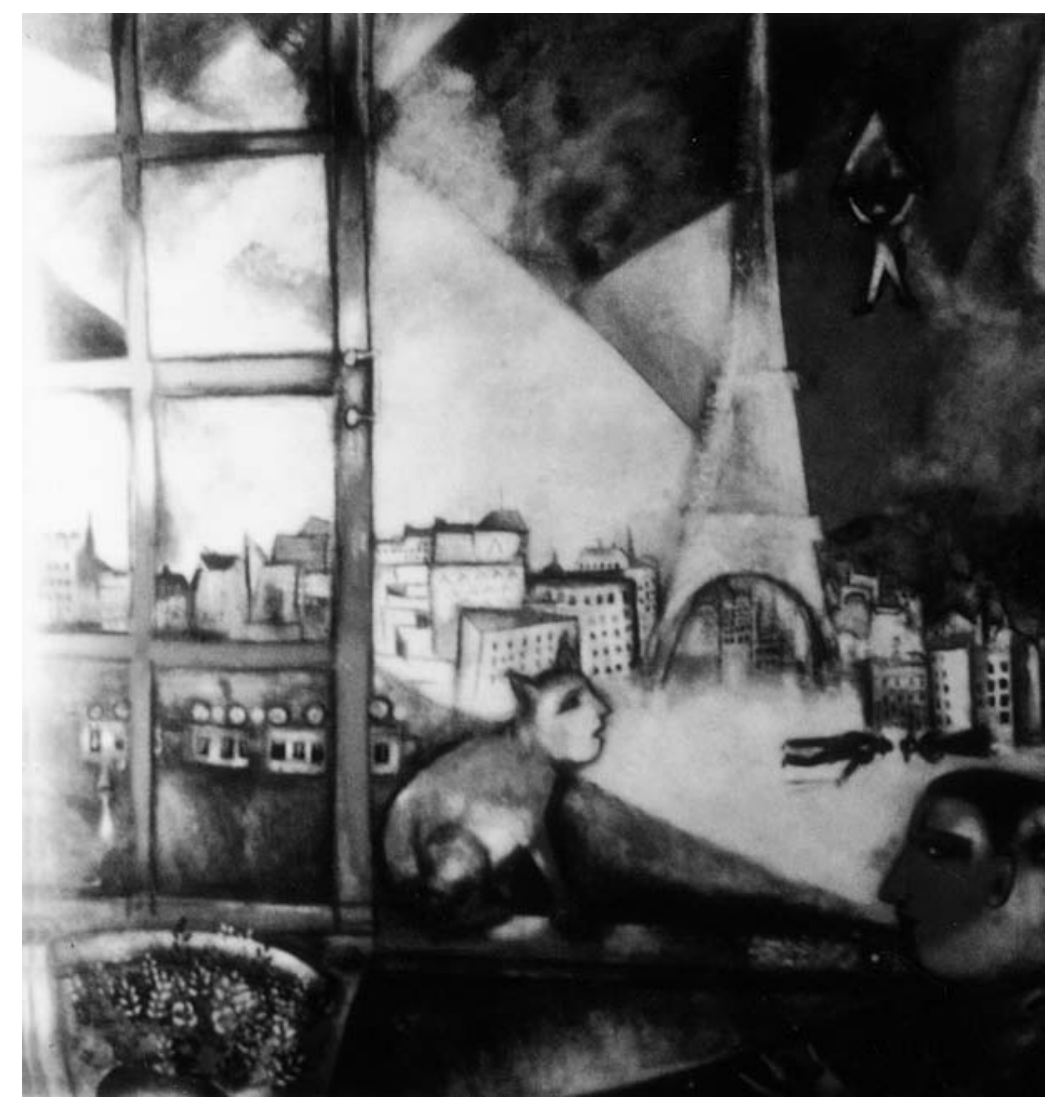

Chagal (1913). "París por la ventana".

Las respuestas son muy diversas, el único grupo formado es el que opina que depende de los criterios de cada uno.El resto: porque le guste a la gente, porque tiene algo de particular, porque es de un artista famoso, porque está hecho por un profesional.

"No se puede saber si es bueno o malo, sólo si te gusta a tí"

Los títulos que dieron a las obras mostradas en las diapositivas fueron, en general, muy descriptivos. Incluimos algunos de ellos:

1. Chagall

"La ciudad de París"

"Sueño del intérprete"

"La ciudad"

Una chica le dio el mismo título que le dio su autor: "París desde mi ventana"

2. Giacometti

"Cuadro de medio Pinocho" 
"Pinocho a medio hacer"

"Marioneta"

"Agujas de reloj"

"Un clavo con propia vida"

"Pistola"

"Degollado"

3. Pollock

"Tela de araña con mosquitos"

"El hormiguero"

"Las cebollas"

"Las letras"

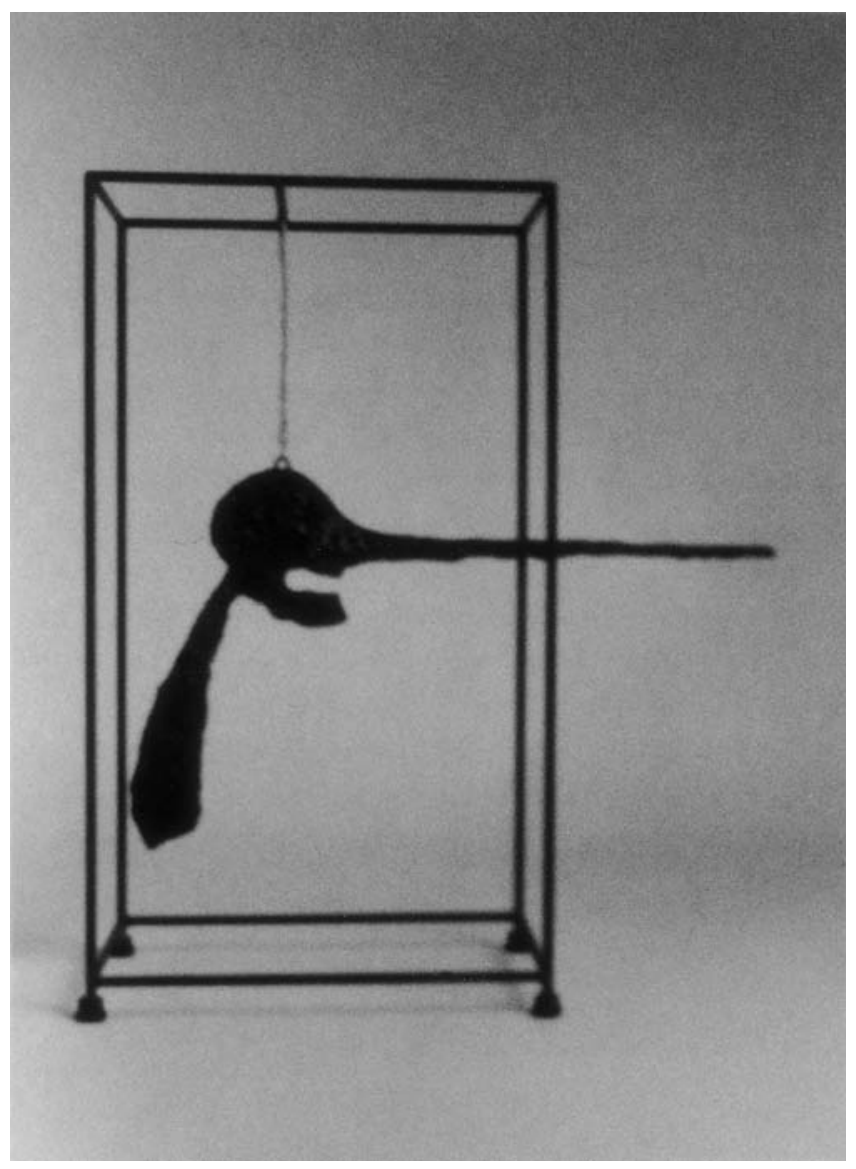

Giacometti (1947).

"La Nariz"

Mediante el diálogo percibieron cómo el pensamiento es un ingrediente imprescindible y nuclear del arte, aunque no basta con el pensamiento porque éste tiene que exteriorizarse en la obra; una niña, sin embargo, mantuvo que "una idea a tí te puede parecer arte " y por ello podría considerarse como tal; aunque estaba convencida de 
ello no supo dar argumentos, parece ser que entendía el comunicar ideas artísticas como arte, ya que a fin de cuentas las transmites.

Mediante la interpretación de las diapositivas experimentaron y tomaron conciencia de dos cosas: que mirar activamente una obra de arte hace pensar, cosa que tuvieron que hacer para poder dar un título a cada una de las obras ( no conocían los títulos de sus autores); y que la experiencia estética es relativa, ya que no a todos les gustaban las mismas obras y de la misma manera y no todos veían lo mismo en ellas. Esta experiencia de la relatividad se vió reforzada al enfrentarles al problema del establecimiento de criterios objetivos para determinar el valor de una obra de arte. En los escritos de los cuadernos se ve bien reflejada esta duda acerca de la universalidad de las cuestiones estéticas. Se observa, sin embago, que algunos se basan en criterios más materiales, lo cual irá escaseando con el paso de los días.

Sienten bastante incertidumbre ante el abstracto pero les gusta mucho buscar formas reales en las manchas y salpicados.

Jackson Pollock (1948).

Detalle de la obra "composición 16"

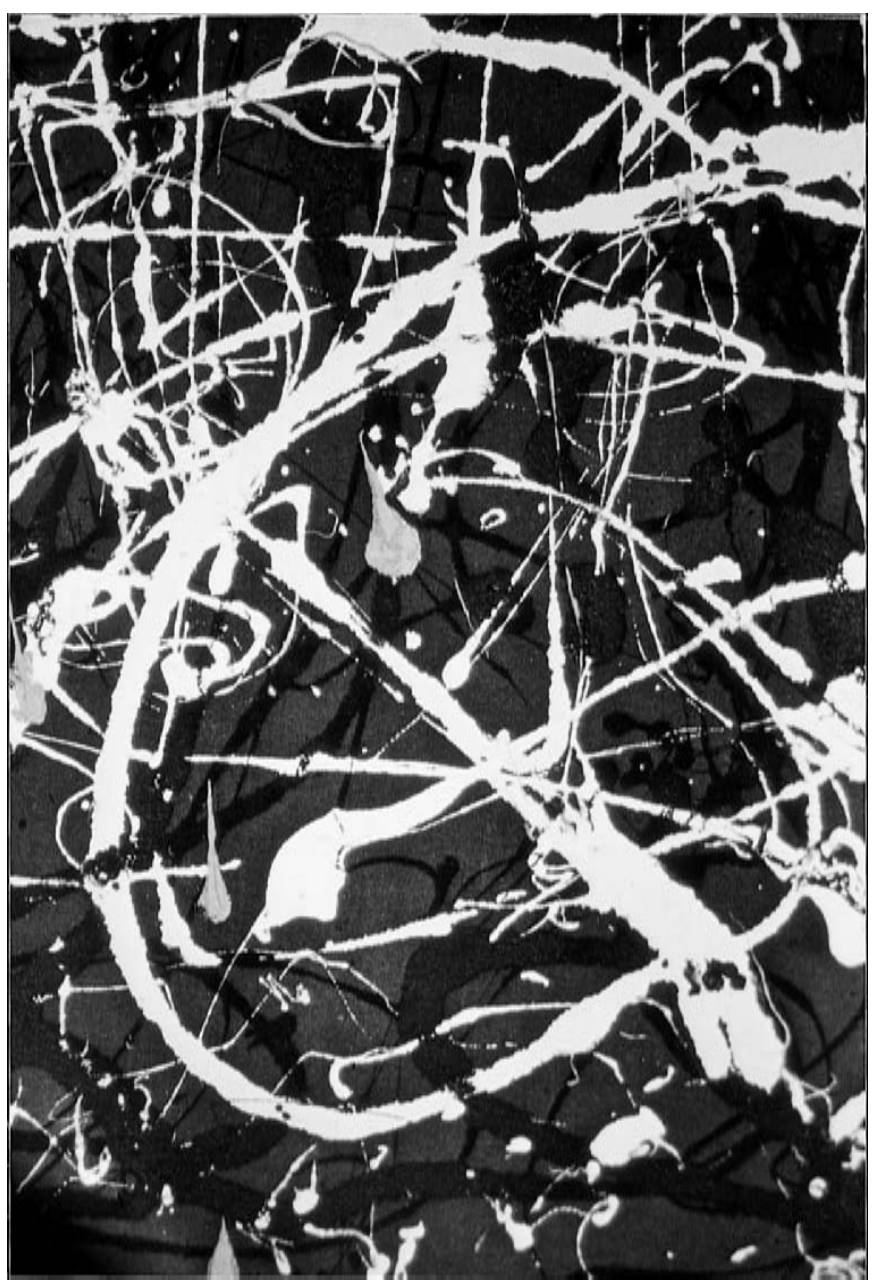




\section{3aㅗ SESIÓN}

\section{Objetivos:}

En esta tercera sesión nos propusimos situar a los niños en el arte como obra hecha desde el punto de vista del artista y, desde este ámbito, discutir entre dos posiciones: el arte como producto de un proceso, o arte en el que se considera que el proceso es el producto. Nuestro objetivo era que los alumnos conocieran y comprendieran algunas claves del arte abstracto.

Contenidos:

Conceptos:

Arte como producto y como proceso

Arte figurativo-arte abstracto

Conocimiento de una postura real: Jackson Pollock

Procedimientos:

Leer

Dialogar

Aprender a ver la diferencia entre figurativo-abstracto.

Producir arte abstracto

Escribir en sus cuadernos las respuestas a las cuestiones que les íbamos a hacer

Actitudes:

Compenetración con el artista

Valoración del arte como expresión dinámica del mundo interno del artista.

Materiales:

Diapositivas:

$$
\begin{aligned}
& \text { Delanay: "Saint Seveint" (1909-1910) (no 4) } \\
& \text { Rothko: "Rojo y azul sobre rojo" (1959) (no 5) }
\end{aligned}
$$

Texto $2^{\underline{o}}$

Pinturas y folios

Radio-cassette y cinta del festival de música electrónica SONAR 98

\section{Procedimientos y realización:}

Lo primero que hicimos fué debatir la diferencia entre dos cuadros uno figurativo y otro abstracto, para que ellos mismos pudieran ir definiendo cuáles son las características de una y otra corriente artística.

Tras ello leímos un texto que hablaba, a modo de cuento, de la evolución de un artista Ilamado Jackson Pollock; por supuesto algunas cosas que se cuentan han sido inventadas, pero la base de su forma de entender el arte sí está presente. Se trata de una artista que pintaba de una forma muy vital y terapéutica, por lo que los resultados finales de la obra no eran para él muy importantes. A nivel histórico su aportación es muy decisiva ya que con esta concepción del proceso artístico como lo primordial, 
abre nuevas vías dentro del arte como el arte procesual, el performance y el Fluxus en las que la obra es una acción etc.

Con el texto se ponía al alumno en una situación; era una propuesta, un juego: unas condiciones como punto de partida para hacer un dibujo fundamentalmente basado en el arte abstracto y la espontaneidad.

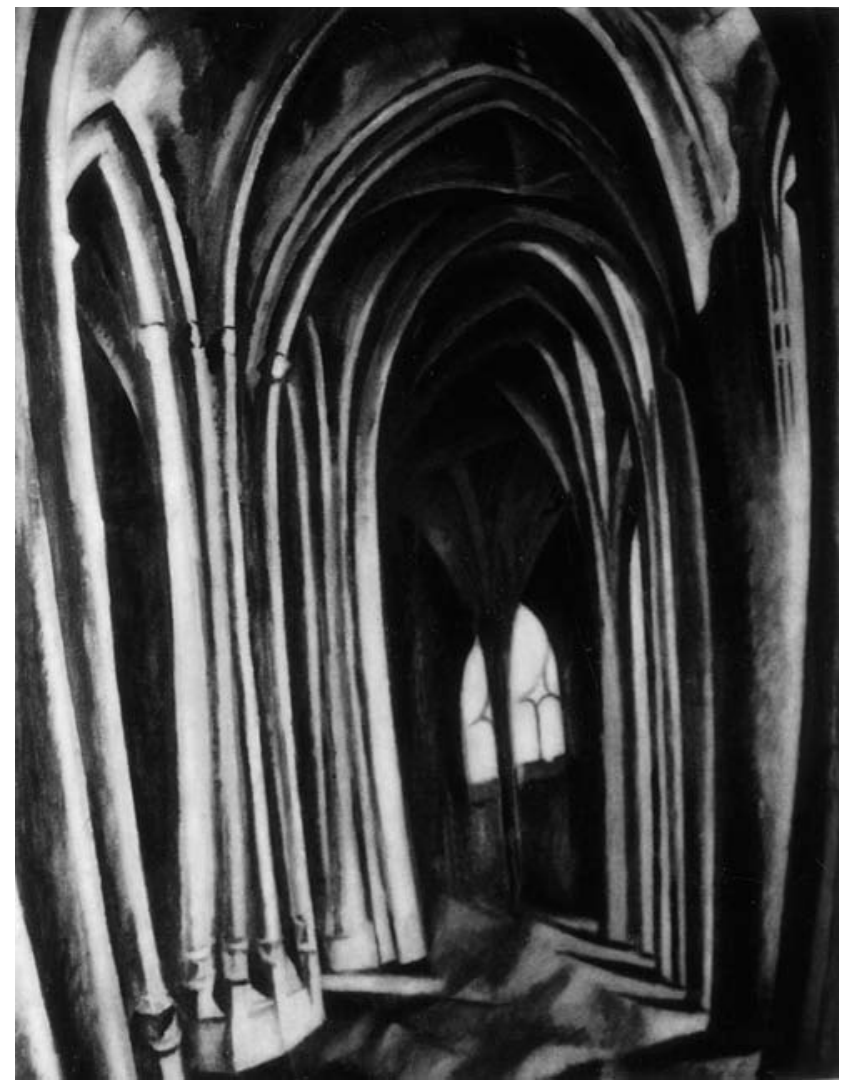

Delanay (1909-1910).

"Saint Seveint"

Tras leer el texto apuntamos de nuevo preguntas en la pizarra para iniciar un pequeño debate:

Durante éste los alumnos se plantearon si era más importante el resultado o el proceso (el disfrute) , y, suponemos que reafirmados por el texto, la mayoría estaba a favor de un arte que servía para uno mismo, por lo que lo principal era el disfrute; entonces les planteamos la siguiente pregunta : "si lo importante es disfrutar ¿todo sería arte?" no saben contestar.

Tras ello procedimos a hacer el dibujo acompañado de una canción del festival de música electrónica SONAR '98.

Les pedimos que contestaran, cada uno en su cuaderno, estas preguntas:

- ¿Qué pretende un artista cuando hace un cuadro? ¿Y tú? 
Queríamos comprobar, uno a uno, cúales eran sus posiciones en torno a las motivaciones de la acción artística creativa, así como saber si ellos se identificaban con tales motivaciones o no.

- ¿Qué crees que es más importante que una obra sea bonita o que nos haga pensar?

Era el planteamiento de una alternativa ( que no es excluyente) que nos ayudaba a enfrentarnos con las dificultades que presenta el arte abstracto, por eso nos interesaba conocer las posiciones de los niños con respecto a ello despues del debate.

- ¿Qué diferencia hay entre una obra abstracta y una figurativa?

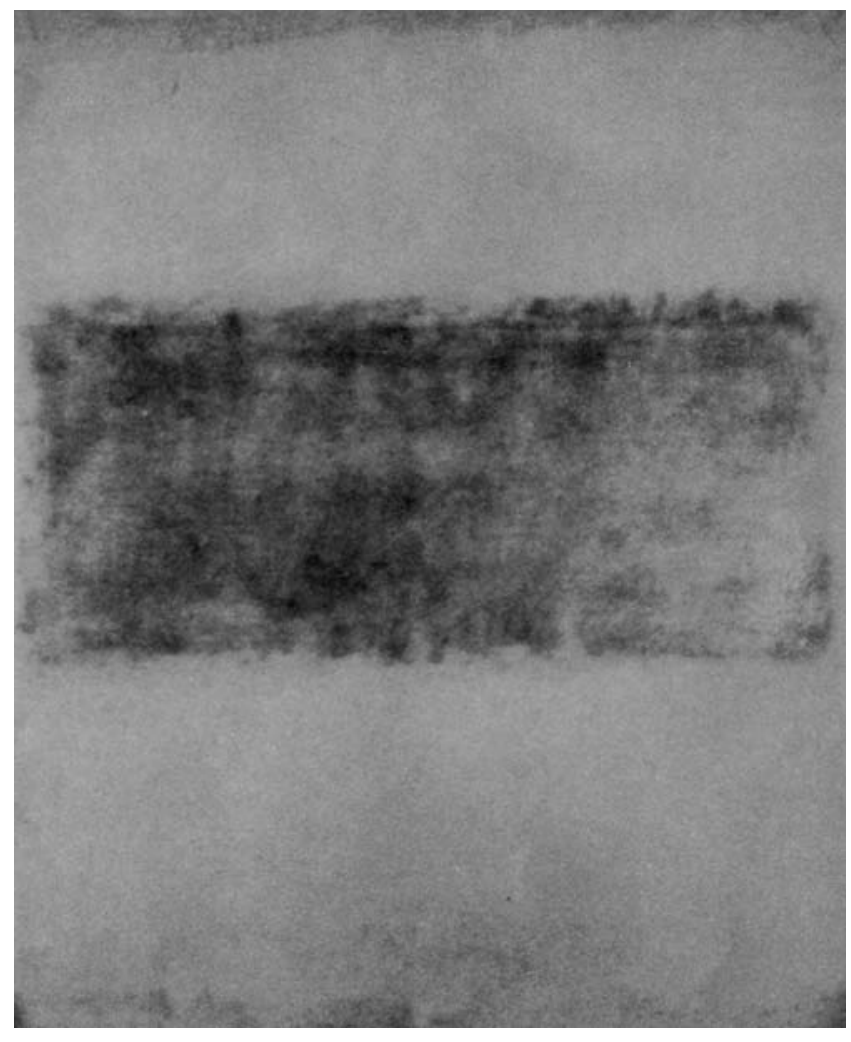

Rothko (1959).

"Rojo y azul sobre rojo"

En el debate sobre la cuestión acerca de si lo importante en la actividad artística es el resultado de la misma o el disfrutar durante el proceso, casi todos los niños estaban de acuerdo en que lo importante era el disfrute y que, por lo tanto, la actividad constituía un fin en sí misma; naturalmente, la consecuencia lógica de defender esta posición es la incapacidad de responder a la pregunta isi lo importante es disfrutar? ¿todo sería arte?; siendo coherentes la respuesta sería afirmativa, pero ellos saben que no es así, algo falla. Ellos tendían a repetir el planteamiento inicial casi ignorando lo que les planteábamos. Sólo algunos avanzaron algo con nuestras propuestas, pero de forma que su opinión inicial no cambiara. 
Fue, sin embargo, un fallo nuestro no haber aprovechado mejor la situación provocada de conflicto para conseguir que ellos mismos descubrieran que ambas cosas no son contradictorias, que una persona puede ser apasionada en su trabajo y disfrutar, pero también esforzarse, dedicarse a un trabajo duro y conseguir resultados gratificantes.

En relación con la primera pregunta del cuaderno, sorprendentemente el grupo mas numeroso dice que el artista trabaja, ante todo, para gustar a los demás; otro grupo más pequeño es coherente con lo defendido en el debate y dice que su intención es disfrutar, el más pequeño habla de gustarse a sí mismo. Dos alumnos han utilizado el concepto de expresión.

Nos damos cuenta de que es importante que cada uno escriba sus respuestas en los cuadernos porque muchas veces no hay coincidencia entre lo que parece que la mayoría piensa en los diálogos comunes y lo que realmente se refleja después en sus escritos. La mayoría cree que a los artistas lo que les mueve es gustar a los demás, más que disfrutar haciendo la obra.

Por otro lado, establecen una diferencia entre las motivaciones propias y las motivaciones de los artistas, no se identifican con ellos. Con respecto a ellos mismos, casi todos utilizan la creación como forma de disfrute, otros para que el resultado le guste a él mismo y un número parecido de alumnos para que guste a los demás. Dos hablan de expresarse.

En cuanto a la segunda pregunta, si es más importante la belleza o el pensamiento, el grupo más amplio piensa que es mejor que nos haga pensar; el siguiente habla de crear una impresión en el espectador; otros de expresión, ilusión y diversión. Solo uno defiende que ha de ser bonita. Eramos conscientes de que ambas cosas no eran contradictorias. El error fue no preguntar por qué ya que no pudimos comprobar hasta qué punto tenían asumida la relatividad de la belleza.

Por último, casi todos han entendido las diferencia entre arte figurativo y abstracto; por lo general identifican lo figurativo con lo material y lo abstracto con el pensamiento.

"En una obra abstracta hay manchas, como si fuera un pensamiento"

"Una obra abstracta es lo que no podemos ver, el interior de las personas"

Como conclusión podemos decir que se cumplieron los objetivos, aunque no resolvimos suficientemente los conflictos.

\section{$4^{\text {a }}$ SESIÓN}

Objetivos:

Situados en el ámbito del arte como obra terminada desde el punto de vista del espectador, nos propusimos que aprendieran a ver el espacio pictórico .

Contenidos:

Conceptos:

Interpretación

El espacio pictórico

Procedimientos:

Ver el espacio 


\section{Dialogar}

Poner títulos a las obras de las diapositivas

Escribir sus lecturas de las mismas

Actitudes:

De discriminación del espacio en la contemplación

Materiales:

Diapositivas de Lucio Fontana: "Concepto Spaciale" (1958) ( nº 6)

Magritte: "La condición humana II" (1935) ( no 7)

Picasso: "Naturaleza muerta española" (1912) (no 8)

Lucio Fontana (1958).

"Concepto Spaciale"

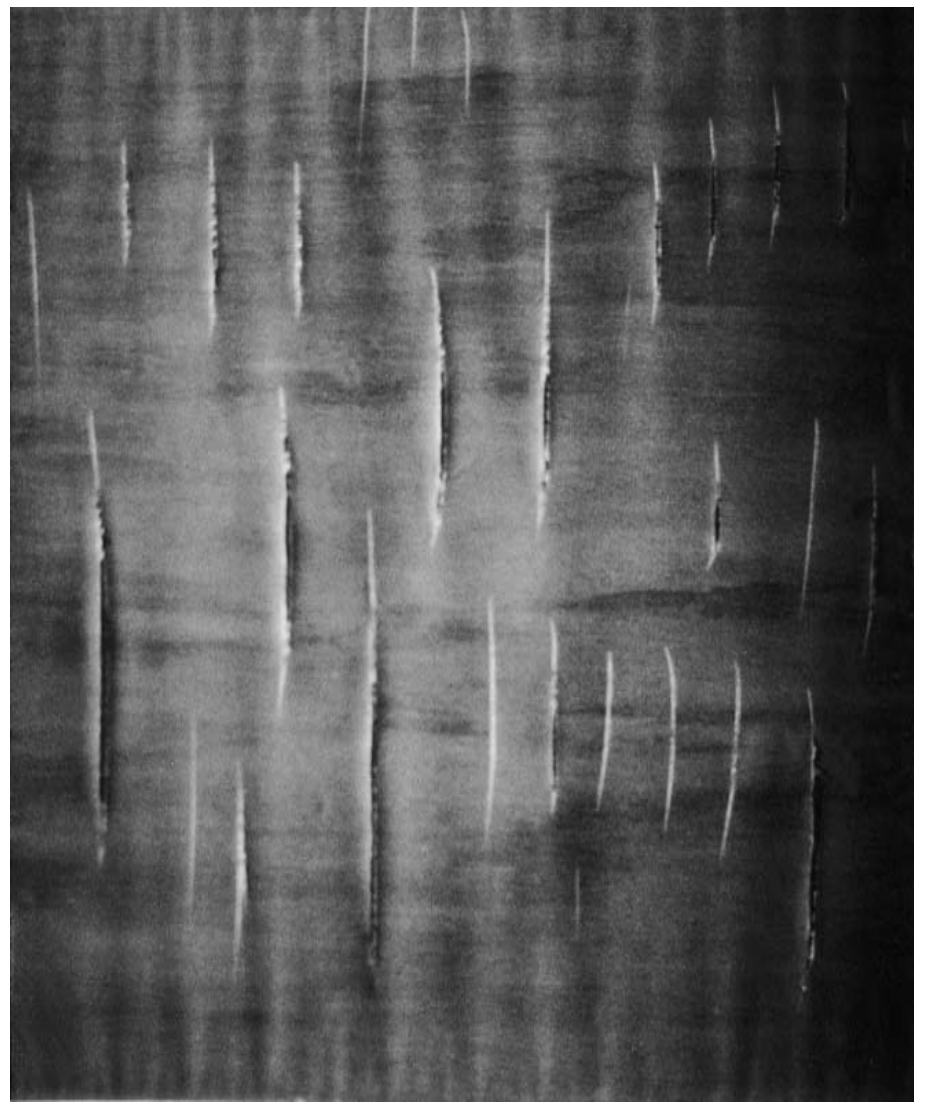

\section{Procedimientos y realización:}

Toda la clase estuvo destinada al comentario de tres obras en las que tenía especial interés el tratamiento que se le había dado al espacio pictórico.

Una de las obras es de Lucio Fontana, un artista que comenzó a reflexionar sobre la naturaleza del soporte pictórico y su tratamiento durante toda la historia. Rasgó la tela de los cuadros como una manera de evidenciar el lienzo y la mentira del espa- 
cio, la perspectiva sobre un soporte bidimensional: un tipo de información ya tan asumida que el espectador casi olvida la naturaleza objetual del lienzo. Por medio de sus rajas nos enseña esa bidimensionalidad y crea la profundidad de una forma real: nos presenta dos planos de profundidad, no los representa.

Comenzamos el debate preguntando acerca de si ese cuadro era una escultura o una pintura; esta idea es una consecuencia de lo que acabamos de comentar. Tras dejar clara su elección, (pintura, escultura o ambas cosas), casi todos tendían a dar una traducción formal y de representación a las rajas de Fontana: peces, garras de león...

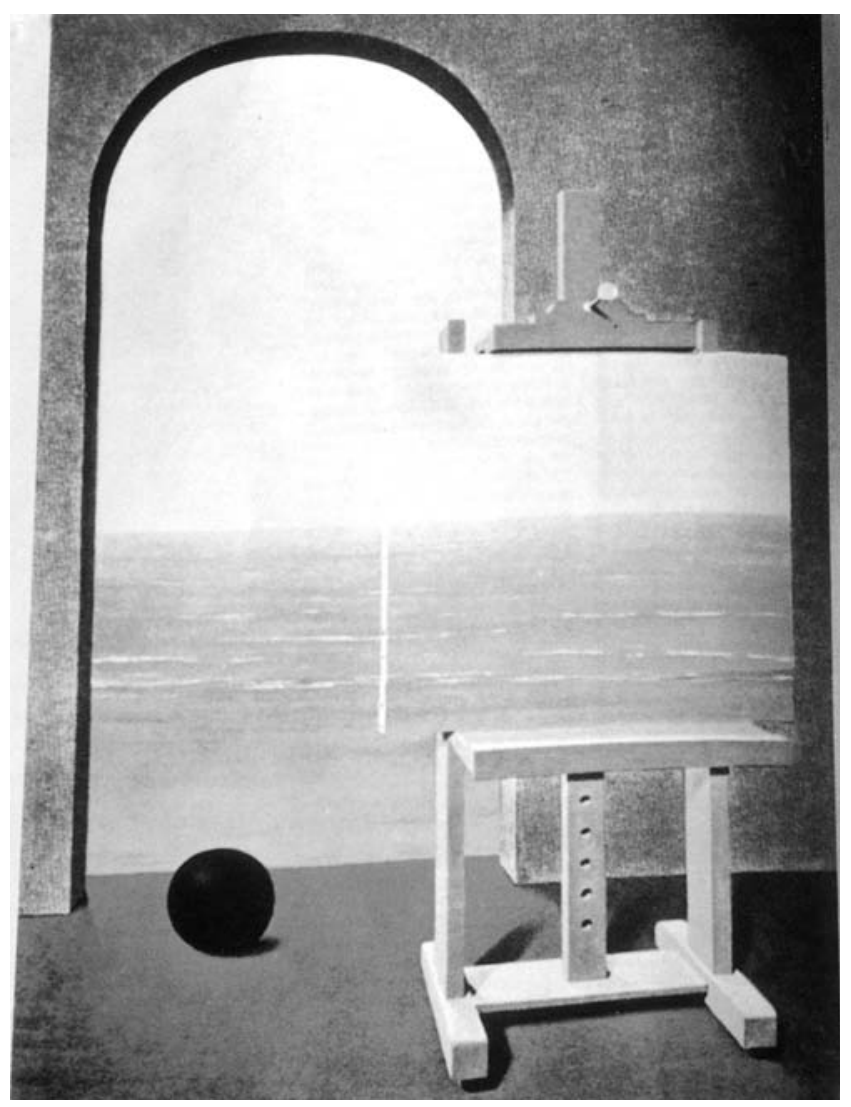

Magritte (1935)

"La condición humana II"

En el momento no creímos conveniente cortar esos razonamientos ya que esperábamos algún pensamiento que pudiera acercarse a los planteamientos de Fontana. No surgieron. Deberíamos haber guiado más la conversación hacia los conceptos abstractos que nos interesaban; además pensamos que hubiera sido más interesante comenzar con el tema de la propia forma de percibir el espacio de ese cuadro y luego pasar a la primera cuestión, porque una vez planteado el conflicto -escultura o pintura- les costaba mucho centrarse en la representación del espacio. Ya habían asumido el carácter objetual de la pieza. La mayoría de los alumnos creían que el cuadro era las dos cosas, escultura y pintura pero ninguno daba argumentos excesivamente elaborados, tampoco se habló de bidimensionalidad y tridimensionalidad. 
El Segundo cuadro es el de un artista surrealista llamado Magritte. Su característica principal es la de presentar la imagen pictórica como una ventana espacial mediante la inclusión de un cuadro dentro de la imagen, que estaba representando el lugar donde se situaba: el cuadro entonces como una continuación o imitación de la realidad. Algunos niños asimilaron esta idea de una forma bastante espontánea, pero tuvimos que dar las claves del cuadro como ventana para que hablaran de algunas de estas cuesiones. Sí es verdad que el darles esta pista les motivó mucho para pensar.

Creemos que debíamos haber presentado esta imagen antes que la anterior porque de esta forma preparábamos mejor a los alumnos para hablar del tema del espacio.

El tercer cuadro era Cubista. Aunque les explicamos brevemente lo que se propone en esta corriente la mayoría veían un espacio vacío o tapado pero ninguno transformado. En un momento dado del debate dimos alguna clave como la de entender esa imágen compuesta por trozos de espejo que nos enseñan diversas partes de la habitación.

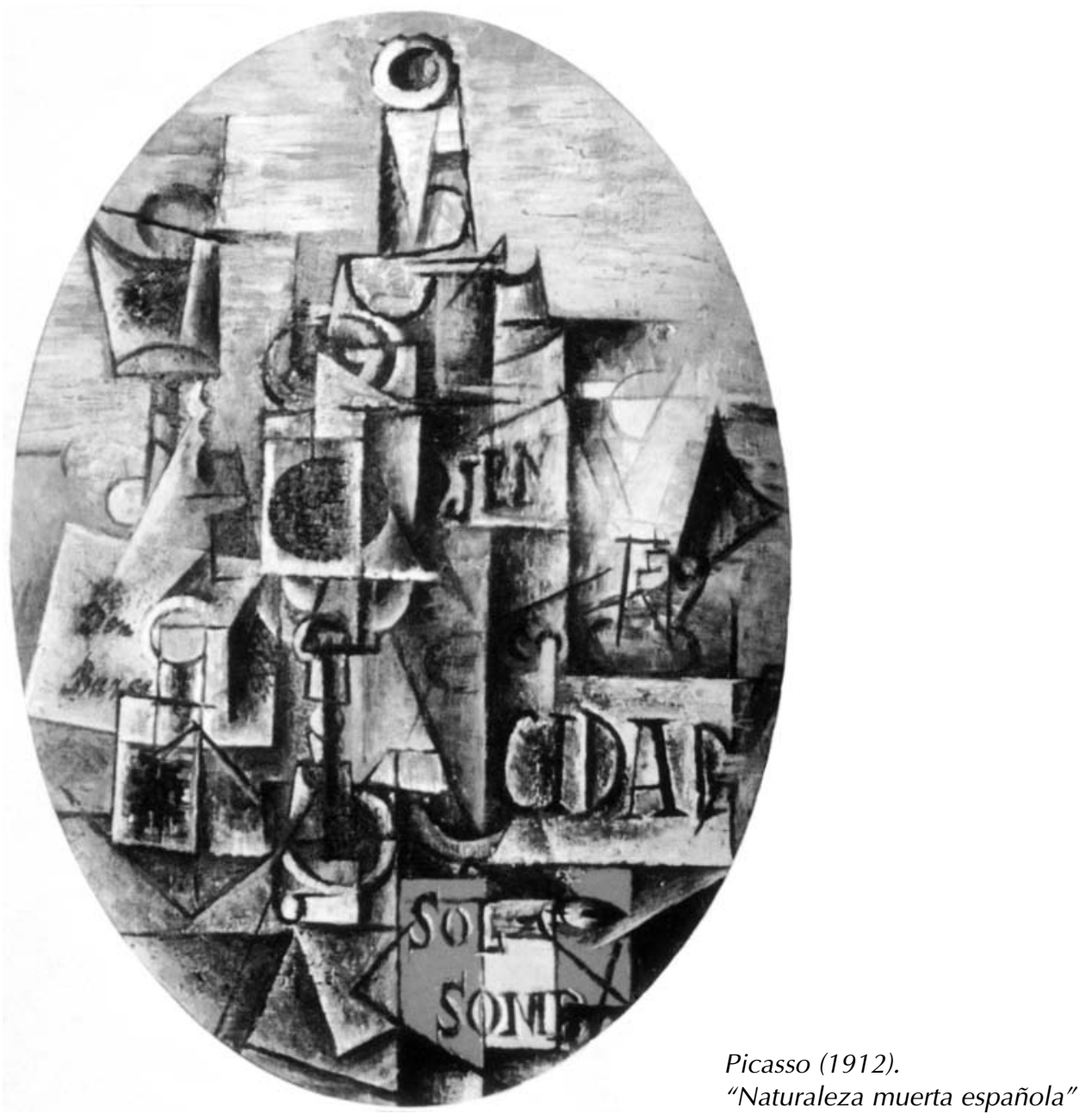


En cualquier caso, sí es verdad que estos conceptos que nosotras tuvimos que ir introduciendo para enfocar mejor los razonamientos, los han asimilado de una forma bastante definitiva.

Les pedimos que escribieran en sus cuadernos la lectura de la obra de Lucio Fontana y los títulos que habían pensado para las otras dos diapositivas.

En la obra de Lucio Fontana tienden a ver formas, causas de las rajas como si fuera el recuerdo de algo que ocurrió, unos más fantasiosos que otros... fue rasgado por un león, con unas tijeras, son las vetas del tronco de un árbol, unos vaqueros rasgados, una cortina de baño rasgada con "una garra".

La mayoría opina que es tanto una escultura como una pintura. La explicación que se le da al hecho de que Fontana lo rasgara es que quería innovar.

Ninguno ha reflexionado sobre una posible evidenciación de la bidimensionalidad del cuadro, de la tela y el cuadro como soporte de creación de perspectiva.

En cuanto a los títulos la pintura de Magritte les sugirió lo siguiente ( sólo transcribimos algunos):

"Dos cuadros encadenados"

"Dónde está el cuadro"

Dos han puesto el mismo: "El cuadro en el cuadro"

"Continuación del mar en un cuadro"

"Ampliación de un agujero"

"El cuadro del cuadro"

"Continuación del mar"

"El espacio infinito encuadrado"

Dos niñas reflexionan en sus cuadernos acerca de si Magritte presenta en realidad dos cuadros unidos. Es interesante, pues se plantea aún más la idea de representación de la representación espacial.

La de Picasso:

"Espacio tapado"

Dos han titulado: "Ciudad desde arriba"

Otros dos: "Espacio reducido"

Varios coinciden en que parece un vertedero.

"Un cuadro situado"

Dos ha coincidido también en:"Habitación cubista"

"Cueva llena de cristales rotos"

"Espacio vacío"

"Puzzle"

En esta sesión vivieron intensamente lo que es la interpretación y, desde luego, pensaron mucho acerca del espacio. Nuestro error en la secuenciación de los temas del debate, que hemos mencionado anteriormente, impidió que los niños comprendieran el mensaje de Fontana a través de su obra. 


\section{5}

\section{Objetivos:}

Para esta sesión disponíamos de dos horas lo que nos permitía trabajar con ideas más complejas. Nos propusimos introducirles en la idea del arte como medio de comunicación, concienciar los elementos que constituyen su estructura y discutir los problemas que plantea.

Contenidos:

\section{Conceptos:}

- El arte como lenguaje

- Artista-emisor - obra de arte-mensaje - espectadorreceptor

- Lo objetivo y lo subjetivo

- Los grandes problemas de la comunicación artística:

- conexión a partir de aspectos subjetivos (experiencia estética)

- lectura aspectos cognitivos (pensamiento)

- problemas específicos del entorno artístico en relación con la sociedad.

Procedimientos:

$$
\begin{aligned}
& \text { Leer } \\
& \text { Reflexionar } \\
& \text { Cuestionar } \\
& \text { Dialogar }
\end{aligned}
$$

Actitudes:

Activas en cuanto a sus relaciones con la obra de arte Ser conscientes de las dificultades que plantea la comunicación artística.

Materiales:

$$
\text { Texto } 3^{\text {o }}
$$

\section{Procedimientos y realización}

La clase comenzó con la lectura de un texto basado en los personajes del primer día, (lo incluimos en los materiales). Tras leerlo procedimos a las preguntas que apuntamos en la pizarra. Después los niños fueron relacionando aquellas que trataban los mismos temas o parecidos.

El debate versó sobre la idea del arte como un lenguaje desconocido, como unos códigos que hay que conocer; $y$, además, que de la misma manera que cada uno tenemos una forma de utilizar el lenguaje hablado, los artistas también tienen una forma distinta de utilizar el plástico.

Los alumnos asumieron sin ninguna dificultad que el arte era expresión, pero ante el hecho contradictorio de que poca gente entiende el arte moderno, no acababan de responder a las preguntas que les hacíamos acerca de cuál podría ser la razón de que 
no entendiéramos muchos cuadros... se quedaban callados o respondían que no todo el mundo sabe expresarse. Sí advirtieron las dificultades de comunicación que presenta el arte.

Probablemente no fuimos lo suficientemente hábiles con las preguntas, o no lo hicimos de la manera adecuada (¿quizás por medio de imágenes,?) para conseguir que ellos descubrieran la importancia de la existencia de elementos compartidos entre artista y espectador. Sí entedieron bien la diferencia entre los conceptos de objetivo y subjetivo.

Antes de finalizar la sesión hicimos una síntesis y un esquema de los conceptos tratados en ella, relacionándolos con las ideas principales trabajadas anteriormente En los cuestionarios se ve reflejado que bastantes alumnos los han incluido en sus conocimientos:

El arte es un medio de comunicación en el que hay los siguientes elementos:

$\begin{array}{ccc}\text { ARTISTA } & \text { OBRA } & \text { ESPECTADOR } \\ \text { Emisor } & \text { mensaje } & \text { receptor }\end{array}$

Podemos entender lo que el artista quiere decirnos si compartimos con él intereses subjetivos, experiencias estéticas, maneras de entender la vida, pensamientos etc.

\section{Evaluación de la prueba final}

Cuando terminamos las sesiones les hicimos un pequeño examen para que fueran respondiendo a las preguntas de un modo reflexivo, no memorístico. Nos interesaba conocer qué contenidos habían asimilado y cuáles no.

¿Para qué es el arte?

La mayoría identifican esta actividad con la expresión; junto con ellos hay una gran parte que lo describen desde el punto de vista del espectador y como tal, entienden que el arte les proporciona un espacio de pensamiento, disfrute y análisis, en el que hay, también, que entender y valorar. Un tercer pequeño grupo ven en él un medio para disfrutar. Algunos lo han descrito como un espacio para la creación. Y, por último, alguno ve en ello un medio para alcanzar la fama.

\section{¿Todos podemos hacerlo? ¿ Por qué?}

La gran mayoría opina que sí ya que su base fundamental es la de expresarse; algunos hablan de que sería necesario poner interés o conseguir gustar, por lo menos a alguien.

Otro grupo más pequeño opina que no todos podemos hacerlo porque no todos tenemos esa capacidad. Algunos piensan que eso depende de los intereses de cada uno y otro pequeño sector piensa que es la sociedad, la opinión pública, la que lo decidirá.

"cada persona tiene un gusto y su gusto es arte" 
¿Es necesario que una pintura o una escultura sean bonitas para que sean arte? ¿Por qué?

La gran mayoría opina que no es necesario porque asumen la relatividad de la experiencia estética; también se ha hablado de esfuerzo, disfrute.

Un pequeñísimo sector opina que ha de gustar a mucha gente y por ello es necesario que sean bellas.

"es arte en el momento en el que te expresas"

"gustará a los que tengan tu gusto"

¿Y que nos hagan pensar?, si crees que podrían hacernos pensar ¿ sobre qué cosas crees que podrían hacernos pensar?

La gran mayoría opina que sí y lo relacionan con el buscar formas, interpretar y conectar con el autor; un grupo más pequeño opina que no es necesario ya que " no todo tiene que hacer pensar", lo pueden ver interesante pero no necesario.

Los temas que relacionan con la práctica artística son el amor, los sentimientos, la guerra, la alegría, la marcha de alguien, las personas y sus vidas, el espacio infinito, el color y la forma.

¿Por qué de un mismo cuadro cada uno ve algo diferente?

La mayoría lo atribuye a una imaginación diferente en cada persona y por la forma de pensar de cada uno.

"Porque una obra puede parecer muchísimas cosas"

"Una escultura me puede parecer una mesa rota y a otro una oveja"

Utilizamos las palabras para comunicarnos, el morse para comunicarnos, el lenguaje de los sordomudos también es para comunicar ¿Crees que el arte podría ser un lenguaje más como el morse o las palabras...?

Todos opinan que sí excepto uno que no identifica el lenguaje con la expresión.

La mayoría de la gente ha coincidido en que el arte es algo que se hace para disfrutar. Yo me pregunto: ¿por qué la mayoría de los artistas sienten la necesidad de enseñar sus obras en exposiciones?

Para hacer disfrutar a los demás es la opción más recurrida, la siguiente es la fama y el dinero (alguien cree que ese artista no entiende de arte). Un pequeño grupo opina que pretenden importar a los demás y dos coinciden en que pretenden comprobar si lo han hecho bien y gusta a la gente.

¿Cuándo crees que termina el proceso artístico de una obra de arte, cuando se termina el cuadro o cuando lo ve la gente? ¿por qué?

Esta pregunta ha sido de las más igualadas. Los que opinan que el proceso artístico termina en la recepción es porque el arte, en realidad se hace para que se vea; otro dice que uno nunca sabe cuándo estará una obra terminada; otro se plantea que si no se ve nadie sabrá nunca de ella y hay quién se plantea qué ocurriría si lo ve alguien sin que el cuadro esté terminado. Por último una persona opina que: 
"Es cuando a tí te gusta cuando la obra se convierte en arte"

Y si una persona hace cuadros que a nadie le gustan pero él disfruta mucho haciéndolos ¿sería arte?, ¿por qué?

Aunque no guste la mayoría defienden que lo importante ha sido la actividad expresiva ("los sentimientos puros ") y de diversión por lo que sí sería arte.

Un pequeño grupo opina que no.

¿Podría ser el arte el mensaje que está entre el artista y nosotros? ¿Por qué?

Sólo hay uno que defiende que el arte no es un mensaje.

"si nos gusta un cuadro ya estamos conectados con el artista"

¿Por qué dos artistas pueden hablar del mismo tema, por ejemplo de las estrellas, y que sus cuadros sean totalmente diferentes? ¿Cuál tendría más éxito?

Las opiniones están muy repartidas, no hay grandes grupos. Un alumno opina que será mejor el que lo haga primero. Un pequeño grupo dice que depende de lo que le guste a la gente. Dos grupos grandes opinan que: uno, será mejor el que a tí más te guste; otro, los dos si lo han hecho con esmero y han disfrutado.

Hay quien dice que será mejor el que tenga mayor capacidad de expresión y otro que será el más famoso.

Y si no coincide lo que un artista ha querido expresar con lo que tú ves ¿Cual de

las dos lecturas es la más importante: la tuya o la del artista? ¿por qué?

La gran mayoría opina que es más importante la idea del artista porque es el punto de partida. Muy pocos consideran que lo importante es lo que uno ve. Sin embargo hay quien dice: "Los dos porque una obra de arte es famosa por lo que el artista pensó y por lo que a tí te hizo pensar"

Si una persona tiene una idea para una obra de arte pero es muy perezosa y es un amigo suyo quien la lleva a cabo y la realiza con su consentimiento, ¿Cual de los dos es el artista? ¿Por qué?

La gran mayoría opina que es quien lo hace porque es el resultado el que la gente va a ver y valorar; otro cree que el que lo hace es quien lo ha sentido durante el proceso. Un pequeño sector habla de la habilidad y el esfuerzo como valores principales.

El grupo que defiende al creador inactivo es de la mitad de alumnos que el anterior.

Dos alumnos defienden que los dos son artistas.

Algunos pensasteis que en el cuadro cubista el espacio había sido reducido, ¿por qué?

Si tú pensabas que el espacio había sido tapado ¿Por qué?

Si tú pensabas que había sido llenado ¿Por qué? y ¿Con qué?

Las palabras que utilizan son: tapado, reducido, lleno de cristales rotos (este último es el único grupo). 
Hay quien ve un espacio vacío y quien piensa que ha sido agrandado porque era un espacio que se repetía continuamente "se llena otra vez en el cuadro"

"Todo el cuadro está tan lleno y apretujado que da la sensación de pequeñez"

"El cuadro ha sido reducido porque se han puesto muchas cosas"

"El cuadro estaba lleno de apariencias"

Dime qué cosas te han gustado y cúales no te han gustado de las clases, ¿Te gusta pensar? ¿Has pensado sobre cosas que antes no habías pensado? Me gustaría mucho saber qué cosas no están bien hechas para pensar en ellas y mejorarlas.

A la mayoría lo que más les ha motivado han sido las diapositivas. Otro grupo más pequeño también ha disfrutado de los debates. Les ha disgustado tener que responder cuestionarios y algunos estaban molestos porque no todos participaban. Casi ninguno ha valorado especialmente haber pensado por primera vez en estos temas aunque muchos no lo habían hecho.

\section{3- Parte: exposición y valoración de los resultados}

Basándonos en el transcurso de las clases, en la lectura de los cuadernos y en la prueba final podemos decir que en relación con los objetivos propuestos hemos encontrado los siguientes resultados:

\section{Asimilación de los conceptos fundamentales}

No han tenido problema en asimilar los conceptos que trabajamos con la precisión que deseábamos. Desde las primeras clases han pensado a partir de su experiencia como creadores y por ello les ha resultado más fácil. En realidad han ido explicitando y razonando sobre ideas que ellos ya tenían aunque de una manera intuitiva.

Podemos valorar que se ha cumplido este objetivo en un $90 \%$.

\section{No hay una solución unica}

Un $80 \%$ busca una opción a las diferentes cuestiones que se plantean pero no de una manera radical y estereotipada, pues casi siempre razonan su opción de forma lógica y perfectamente válida. Pensamos que esas decisiones podrían modificarlas dependiendo del caso propuesto. En definitiva asumen la relatividad de todas estas cuestiones. Alguno de ellos, sin embargo, se muestra más radical y dogmático pero en una proporción mínima. Suele coincidir que son estos mismos que hablan de dinero, fama y opinan en términos materialistas.

\section{Interpretación y reflexión}

Un $90 \%$ ha trabajado a ese nivel, pero a duras penas muchas veces. Costó conseguir un ritmo en ese sentido; les gusta más exponer su postura que razonarla y defenderla frente a otras contrarias porque asumen que el arte es algo tan individual que ninguna problemática social tiene por qué afectar al trabajo del artista. 
En realidad nos preparamos para un entorno de prejuicios. Pensando en la actitud casi siempre intransigente de la sociedad con el arte moderno, quisimos mostrar el lado del artista poniendo a los alumnos en su lugar. El problema que surgió fue que ellos no habían adquirido todavía esos prejuicios y se mostraban más extrañados que escépticos con el trabajo de los artistas modernos. De esta forma, su propia relatividad sumada a la que nosotras quisimos transmitir produjo que ante cada dilema difícil ellos se acogieran a la idea del arte como medio para disfrutar y el gusto propio como principal criterio. Esto difilcultaba que se enfrentaran a diversas problemáticas como por ejemplo al hecho de que hay determinados conocimientos tanto para ver como para hacer: les planteamos cuál era la solución al hecho de que ellos, como artistas querían disfrutar pero como receptores querían entender; no daban respuestas. También es cierto que no tienen demasiados ejemplos de esta realidad.

Lo que más les motivaba era la lectura o comentario de las obras ya que todos se sentían capaces de opinar y estaban ansiosos por encontrar cosas nuevas dentro de un cuadro. Pensamos que este es la mejor vía hacia el tratamiento de temas nuevos como fue el caso de la sesión en la que tratamos conceptos específicos como es el del espacio pictórico. Por medio de una buena planificación de diálogo y una estudiada secuenciación de las cuestiones se puede llegar a reflexiones muy interesantes, sobre todo partiendo del hecho de que ellos tienen ganas de participar.

\section{Elección de opciones}

El $80 \%$ de los alumnos ya confiaban en que su opinión no era invalidada por las contrarias por ello no muestran especial interés en defender exasperadamente la suya. Esto es algo que fuimos comprobando con los debates.

\section{Acercamiento y discusión sobre los códigos artísticos del arte contemporáneo}

Pequeñas pinceladas sin un ánimo instructivo, más como vía para pensar en otras cuestiones: el espacio, el proceso artístico, el gusto y la diversidad de opiniones. No creemos que se les haya capacitado para enfrentarse a ellas pero desde luego sí han experimentado cómo estas obras aparentemente anodinas pueden ser motivo de debate y reflexión; así el caso de la obra de Lucio Fontana que por ser una tela rasgada suele parecer carente de significado.

\section{Experimentación del proceso artístico desvinculado al resultado final}

Un 30\% de la clase no entendió la propuesta pero sin embargo sí asumió la importancia de tener una experiencia creativa gratificante. En estas edades es muy corriente que los niños intenten dibujar cosas concretas y se sientan frustrados por no conseguir el parecido que pretendían por eso nos pareció interesante plantearles que el resultado era el mismo proceso, enseñándoles una de las facetas del arte de carácter más lúdico.

El error que cometimos tiene que ver con lo que ya mencionábamos anteriormente y es que esta experiencia potenciaba el relativismo. Principalmente porque planteamos 
mediante un cuento la perspectiva de un artista real que se había centrado más en el proceso. El ver redactada y fundamentada esta opción creativa reforzaba su postura.

Por otra parte no se puede decir que los trabajos estuvieran conectados con la experiencia estética que debía aportarles la música ya que hubiéramos necesitado un lugar para ponerla a todo volumen de modo que se sumergieran más aun en la actividad, es decir en el proceso.

También hemos experimentado que bastantes alumnos sienten incompleta su obra si no hay elementos de tipo figurativo, probablemente condicionados por sus esquemas previos.

\section{Acercamiento a la problemática social del arte}

Este es el principal punto que se vio afectado por los problemas que hasta ahora hemos ido mencionando. El enseñar que el arte no debe estar continuamente condicionado por los resultados es preferible, en esta etapa, a dar una visión elitista y exclusivista, pero eso derivó en que los alumnos perdieran interés por las dificultades con las que se enfrenta un artista dentro del sistema del arte. Ya expliqué las razones en el punto 4. Este objetivo, por tanto, no llegó a cumplirse.

Nuestro empeño por no imponer ningún tipo de información nos condujo a dejar que algunos planteamientos aparecieran como incompatibles. La razón de que este último objetivo no se haya cumplido pudo ser el no trabajar suficientemente el concepto de intencionalidad. Así mientras casi todos opinan contundentemente que el arte puede ser una vía de comunicación creen que si el artista no comunica tiene el mismo valor; por otra parte ninguno ha pensado que el que los artistas expongan su obra nazca por una necesidad de expresión. Pero conceden gran importancia a la recepción ya que la mitad de la clase opina que el proceso artístico termina cuando el espectador ve la obra y es que da la sensación que en el fondo, no relacionan la expresión con la comunicación,(véase pregunta 9 y 10 del cuestionario final).

Dentro de este objetivo sí es verdad que en varias ocasiones los alumnos muestran haber asimilado que la obra es un eslabón entre el artista y el espectador y no como algo independiente de la sociedad.

Parece ser que han asimilado conceptos sueltos sin entrelazarlos o aplicarlos unos a otros, estadísticamente no puede decirse que las respuestas sean del todo coherentes unas con otras.

\section{Conclusión}

Nos hemos dirigido hacia un campo lleno de contradicciones y problemáticas sin solución única. Principalmente nos interesó, una vez más, acercar el arte a la vida y de esta forma no desvincularlo de la sociedad. Lo principal, como reflexión final, es que aunque no se hayan conseguido ciertos objetivos o inclusión de determinados conceptos, sí se ha considerado el arte como una realidad inherente a la propia vida de los niños, desde la que han podido valorar tanto su posición como espectadores, como su posición como creadores. Nos parece interesante abrir estos espacios dedicados al arte moderno que tan ajeno resulta para la mayor parte de la sociedad, cuan- 
do es un reflejo directo de la misma y un punto de partida para tratar cuestiones sobre ella. Nos proponemos continuar este proyecto, depurando determinados fallos que, como ya expusimos, pudieran crear interferencias en nuestro cometido.

Si algo nos ha mostrado esta experiencia es cómo el arte no sólo es una vía de comunicación artista-espectador, sino además un elemento generador de pensamiento, por eso consideramos que la inclusión del arte entre las materias de enseñanza es importante. Paralelamente es interesante cómo, por medio de estos debates, u otros que nada tuvieran que ver con las polèmicas artísticas, se puede proporcionar al niño un aprendizaje artístico que le permita entender los códigos del arte moderno, una carencia social muy común. Cualquier tema que se quiera abordar en un debate puede ser representado por una imagen artística, ya que esta disciplina avanza en paralelo a la sociedad. De esta manera nos adentramos en el pensamiento artístico, filosófico, económico, político...aunque esto quede por experimentar.

Estas son reflexiones resultantes de la experiencia que consideramos de las más preciadas.

"Es cuando a tí te gusta cuando la obra se convierte en arte"

"Porque el arte es una de esas cosas en las que es muy fácil dar ejemplos pero, sin embargo es tan difícil definir"

\section{Bibliografía}

ÁLVARO, M.I. et al. 1974. Ver el arte, Zaragoza.

ARGÁN, G.C. 1991. El Arte Moderno, del Iluminismo a los movimientos contemporáneos, Madrid : Akal/Arte y Estética.

ARNHEIM, R. 1985. El pensamiento visual, Buenos Aires: Eudeba.

AUSUBEL, D.P. 1983. Psicología educativa: un punto de vista cognoscitivo. D.P. Ausubel, J.D. Novak, H. Hanesian. Mexico: Trillas (2a Ed.).

BARRAGÁN, J. 1992. Para saber más, Cuadernos de Pedadogía, (208): 32-36, 43 REF.

BAYO MARGALEF, J. 1987. Percepción, desarrollo cognitivo y artes visuales, Barcelona: Anthropos.

BLOOM, B. 1975. Evaluación del aprendizaje, Benjamin S. Bloom, J. Thomas Hastings, George F. Madaus. Buenos Aires: Troquel.

BORRÁS GUALIS, G. 1993. La Historia del Arte en la encrucijada, Artigrama (10), 45-53. BOZAL, V. 1993. Modernos y Postmodernos, Madrid: Historia 16.

CALAF, R. et al. 1998. Aspectos didácticos de las ciencias sociales, Zaragoza: I.C.E.

COLL, C. 1988. Psicología y curriculum, Barcelona: Laia.

EISNER. 1971. Educating Artistic Vision, New York: Mac Millan.

EQUIPO DIDART. 1996. El arte, argumento educativo, Cuadernos de Pedagogía, (252): 18-21

FERNÁNDEZ CURSACH. 1995. Entre el cielo y la tierra, Cuadernos de Pedagogía (235): 50-54, 7 REF.

GONZÁLEZ, A.E. 1989. Las claves del arte. Ultimas tendencias, Barcelona: Ariel. 
HUSSERL, E. 1990. La crisis de las ciencias europeas y la fenomenología transcendental, Barcelona: Editorial Crítica.

LIPMAN, M. 1992. Filosofía en el aula, Madrid: Ediciones de la Torre.

LUCIE-SMITH, E. 1991. Movimientos artísticos desde 1945, Barcelona: Destino.

MERCHÁN FIZ, S. 1985. El Universo del arte, Barcelona: Salvat.

MERCHÁN FIZ, S. 1992. El arte en la cultura moderna, Madrid: Alianza.

MARTíNEZ MARZOA, F. 1973. Historia de la filosofía, Madrid: Ediciones Istmo.

NIETZSCHE, F. W. 1973. El nacimiento de la tragedia, Madrid: Alianza.

ORTEGA Y GASSET, J. 1983. ¿Qué es filosofía?, Madrid: Revista de Occidente.

VVAA. 1999. Didáctica de las artes plásticas, Madrid: I.C.E. de la Universidad Complutense de Madrid.

VVAA. 1995. Educación plástica y visual, Madrid: Santillana.

VVAA. 1997. Historia del Arte, Madrid: Alianza. 